Review Article

\title{
Applicability Analysis of Inspection and Monitoring Technologies in Wind Turbine Towers
}

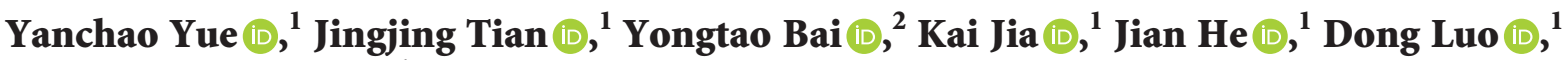 \\ and Tangbing Chen (iD)
}

${ }^{1}$ School of Human Settlements and Civil Engineering, Xi'an Jiaotong University, Xi'an 710049, China
${ }^{2}$ School of Civil Engineering, Chongqing University, Chongqing 400045, China

Correspondence should be addressed to Dong Luo; luodong@xjtu.edu.cn

Received 1 March 2021; Revised 30 March 2021; Accepted 24 April 2021; Published 30 April 2021

Academic Editor: Chengwei Fei

Copyright (C) 2021 Yanchao Yue et al. This is an open access article distributed under the Creative Commons Attribution License, which permits unrestricted use, distribution, and reproduction in any medium, provided the original work is properly cited.

Wind turbines are one of the key systems in wind energy development. The wind tower supporting the whole wind turbine is a towering structure, which has been affected by installation, transportation, environment, and other factors. Furthermore, it is prone to experience other quality problems that would be difficult to detect for wind turbine towers. Therefore, the key to maintain the wind tower structure and to ensure the normal operation of a wind turbine is to carry out comprehensive and detailed detection and monitoring studies during its service stage. This paper sorted out several common quality problems including structural damage, deformation, flange bolts loosening, and corrosion of wind tower and relevant research on the detection and monitoring of these quality problems. In addition, some nondestructive testing technologies are introduced, including the ultrasonic phased array, time of flight diffraction, magnetic memory, acoustic emission, fiber Bragg grating and piezoelectric impedance, and applications in wind turbine towers.

\section{Introduction}

With the exhaustion of traditional nonrenewable resources and the deterioration of the environment, the development of clean and renewable energy such as wind energy has been accelerated [1]. Wind turbine is the main structure for wind energy development, whose components include the wind tower which is the supporting part of the whole structure and works under the dynamic load directly $[2,3]$. The wind tower plays a vital role in ensuring the normal operation of the wind turbine. However, the wind turbines are often exposed to the harsh environment and subjected to large fatigue loads [4]; therefore, the wind tower may suffer serious quality problems or even collapse, causing huge economic losses. Carrying out the structural health detection and monitoring of the tower can reduce the maintenance cost and downtime of wind turbines [5], making it an indispensable and important part in wind power engineering.

However, the current state-of-the-art methods on detection technology of wind towers are very extensive and there is no systematic sorting. Therefore, this paper firstly summarizes some quality problems of wind towers including structural damage, deformation, flange bolt loosening, and corrosion, as well as the developed research of other authors on the corresponding detection and monitoring system. In addition, the principle, advantages, and limitations of several nondestructive testing technologies are introduced, including ultrasonic phased array technology, time of flight diffraction technology, magnetic memory technology, acoustic emission technology, fiber Bragg grating technology, and piezoelectric impedance technology. These nondestructive testing techniques are widely used in various engineering structures and are relatively advanced, specifically, this paper mainly introduces the application of these techniques in the detection of wind turbine towers. It is expected to provide some reference for the detection and monitoring of wind turbine towers in the future. Although the inspection and monitoring technology of the wind tower has gradually matured, there are a few reliability analyses about it. The existing studies are more related to the analysis 
of the life cycle and failure capability of the turbine blade structure [6, 7], Fei et al. proposed MRSM several models for dynamic nonlinear responses of failure capacities for turbine blisk responses and a probability-based prediction method for turbine blades. Due to the aforementioned, the reliability analysis of wind towers based on detection data needs further research.

\section{Common Quality Problems and Related Research of Detection and Monitoring Methods of Wind Turbine Towers}

2.1. Damage Detection of Wind Towers. Damage including machinery fault is a vital cause of structural failure, making it an important part of structural health detection and maintenance [8]. One common characteristic of damage is the loss of stiffness which can lead to the change of the structural vibration response $[9,10]$ from the point of dynamics. Therefore, it is a primary method to detect damage based on structural vibration characteristics (e.g., natural frequency, damping, and modal shapes) [11].

There are numerous advanced research studies on damage detection based on structural vibration characteristics of wind towers.

Pacheco et al. [12] used sensors to track the mode shapes and natural frequency of a $2 \mathrm{MW}$ wind turbine in operation, and then changed the number and distribution of sensors on the wind tower to conduct operational modal analysis (OMA). The results showed that it takes more time to determine the damage of a wind tower when the number or the quality of sensors is reduced. Additionally, detection results using a few sensors of good quality are often better than a large number of low-quality sensors. If placed properly, one biaxial sensor of high quality can achieve satisfactory results of damage detection on the wind tower.

Kim et al. [13] also studied the damage detection method based on structural vibration characteristics. Numerical accelerometer signals along the direction of the tower and blade in the dynamic wind field are used for calculations in the OMA, and the modal characteristic differences calculated from it are used to detect the damage of offshore wind turbines. In addition, the study allowed obtaining a large amount of structural health monitoring data of one wind turbine by analyzing the natural frequency, displacement mode shape (DMS), and curvature mode shape (CMS) of the tower and the blade, which can serve as the basis for damage detection.

Kim et al. [14] applied the damage detection technology based on vibration characteristics to conduct damage detection and structural health monitoring of a wind turbine. By comparing the results of laboratory tests and finite element analysis, they studied the dynamic characteristics of a wind turbine tower with different damage locations.

On the basis of this detection method, $\mathrm{Hu}$ et al. [15] compared two types of damage of wind turbines. They studied the damage of the tower and blades and the corresponding change of vibration characteristics caused by the decrease of stiffness. The results showed that the vibration characteristics are more sensitive to the damage of the wind tower rather than the blades, indicating that the tower structure plays a vital role in the normal operation of the wind turbine.

Benedetti et al. [16] numerically simulated the cracks in the key parts of a wind tower and estimated the typical inservice loading conditions of the tower based on the vibration characteristics; in addition, radial strain sensors are arranged in key parts of the tower to detect cracks. In order to further study the abnormal distribution of strain caused by the crack propagation, three strategies were compared, including strain peak near crack tip, strain release in the region above the fracture, and strain difference between adjacent sensors.

2.2. Deformation Monitoring of Wind Towers. The wind turbine towers are slender structures with large flexibility, which tend to have large deflection deformation under the long-term action of transverse wind loads, resulting in the tilt of the tower. As shown in Figure 1, the center points of the wind tower at different heights $C_{1}, C_{2}, \ldots, C_{n}$ are not on the plumb line. This will amplify the dynamic response of the top of the wind tower and even lead to the collapse of the tower cylinder [17]. Therefore, deformation monitoring is also an indispensable part of the structural health monitoring of wind towers.

The traditional monitoring method of a wind tower is to measure its perpendicularity using a total station, which is time-consuming and laborious. Therefore, a 3D laser scanner has been applied as a new efficient method to monitor the tilt degree of the tower. Su et al. [18] and Xie et al. [19] used a 3D laser scanner to collect 3D data of separate wind turbine towers and processed these data with different analysis software to obtain coordinates of center points at different heights of the towers which are used to calculate the tilt angle. In addition, by comparing these calculated results with the ones obtained synchronously by the total station, it is proved that the $3 \mathrm{D}$ laser scanning technology can meet the accuracy requirements of the perpendicularity measurement of the wind tower and is more comprehensive and efficient than the total station.

Fiber Bragg grating sensor is a common sensor for measuring structural strain, which can be used in deformation monitoring as well, and its principle is introduced in detail in Section 3.5. Bang et al. [20] developed an array fiber Bragg grating sensor and applied the measured strain to the deflection estimation of wind towers based on the straindisplacement transformation method. In order to verify the reliability and practicability of this method, a field monitoring test was carried out for a 1.5 MW wind turbine, which successfully completed the strain measurement and shape estimation of the tower. In addition to the tower deformation monitoring, the fiber Bragg grating strain sensors are often used to detect the shape and deflection of blades since they will not be affected by electromagnetic interference, lightning, and electronic noise [21].

For the offshore wind turbine, besides the transverse dead load, the impact of waves and hull will aggravate the 


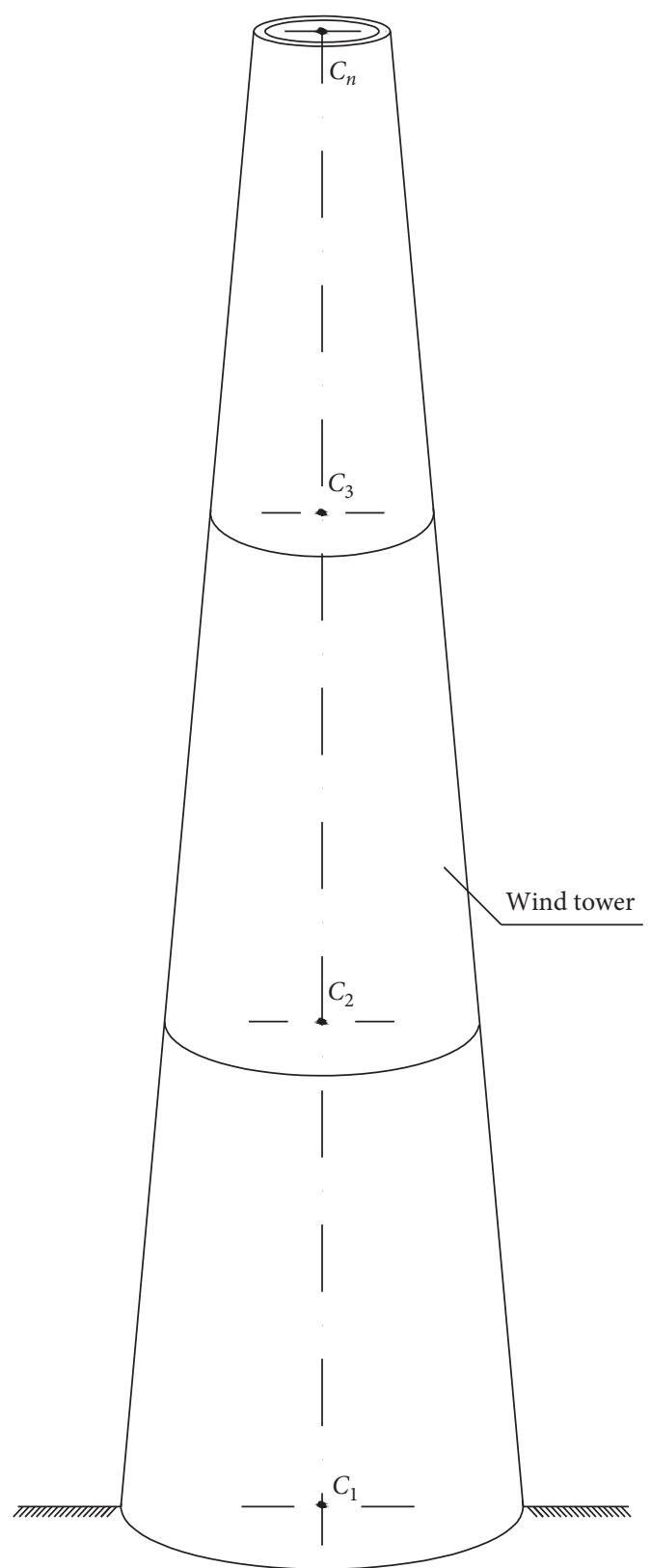

FIgURE 1: The schematic of wind tower.

deformation of the wind tower. Visual inspection is a traditional technology used to measure the perpendicularity of offshore wind towers; however, the detection results of this method will have errors since the verticality of the camera cannot be guaranteed when scanning underwater. To solve this problem, Shan et al. [22] proposed a surface deformation detection method based on a parallel stereo vision model, developed a surface deformation measurement system based on this method, and conducted a deformation test of an offshore wind turbine model under the impact of ships. Results verified the practicability and reliability of this measurement system and provide an efficient and accurate method for the deformation monitoring of offshore wind turbine towers in the future.
2.3. Detection of Flange Bolt Loosening. In wind towers, the flange represents a common connection method, which needs bolts to tighten up as shown in Figure 2. Under the repeated action of wind loads, bolts are prone to become loose, which will seriously affect the integrity and reliability of the tower. Piezoelectric impedance and vibration characteristics are two common principles to detect the bolt loosening.

Bolt loosening will decrease the structural stiffness, leading to the change of vibration characteristics. He et al. [23] developed several vibration tests before and after the bolt was refastened for six separate towers which have different bolt loosening conditions, respectively. Large-scale test data are obtained and shows that the vibration energy of the tower barrel is mainly concentrated on the first-order vibration, and among all vibration characteristics, bolt loosening is most sensitive to the change of first-order phase difference of the upper and lower flange rather than the firstorder natural frequency. This conclusion is confirmed by the study of Chen [24] using finite element modeling analysis.

Piezoelectric impedance is another effective technique to detect bolt loosening. Its principle is introduced in detail in Section 3.6. Tang et al. [25] detected the tightness of flange bolts through five piezoelectric plates and obtained the law between several different detection indexes and the position and degree of bolt loosening. Results showed that structural difference has the least influence on the square root of the standardized rate of all the detection points. Nguyen et al. [26] proposed a hybrid detection scheme combining the two principles of vibration and impedance and conducted vibration and impedance tests on the joint bolts of the labsized wind tower model to detect their loosening and the tests verified the feasibility of the detection method.

In addition to the above-described studies, Park et al. [27] proposed a new vision-based bolt loosening detection technology for wind towers, based on the principle of image processing technology. Specific detection steps include image acquisition, segmentation of each nut, line detection, nut angle estimation, and bolt loosening detection. Furthermore, a model of a flange with 32 bolts was used to simulate the actual flange connection of the wind tower, and the loosening of bolts was experimentally detected, which verified the feasibility of this technology.

2.4. Corrosion Detection of Offshore Wind Turbine Towers. Offshore wind power is more abundant than onshore wind power, which is of higher development value. However, compared with onshore wind turbines, offshore wind turbines are in the harsh environment of alternating dry and wet, salt, fog, and seawater, making corrosion of towers a serious problem [28]. Corrosion will cause stiffness reduction of wind towers [29], which is a major part of the cost of offshore wind energy development [30]; therefore, corrosion detection is extremely important for controlling the maintenance cost of the offshore wind turbine.

However, the remote location of offshore wind turbines seriously limits the application of in situ corrosion detection 


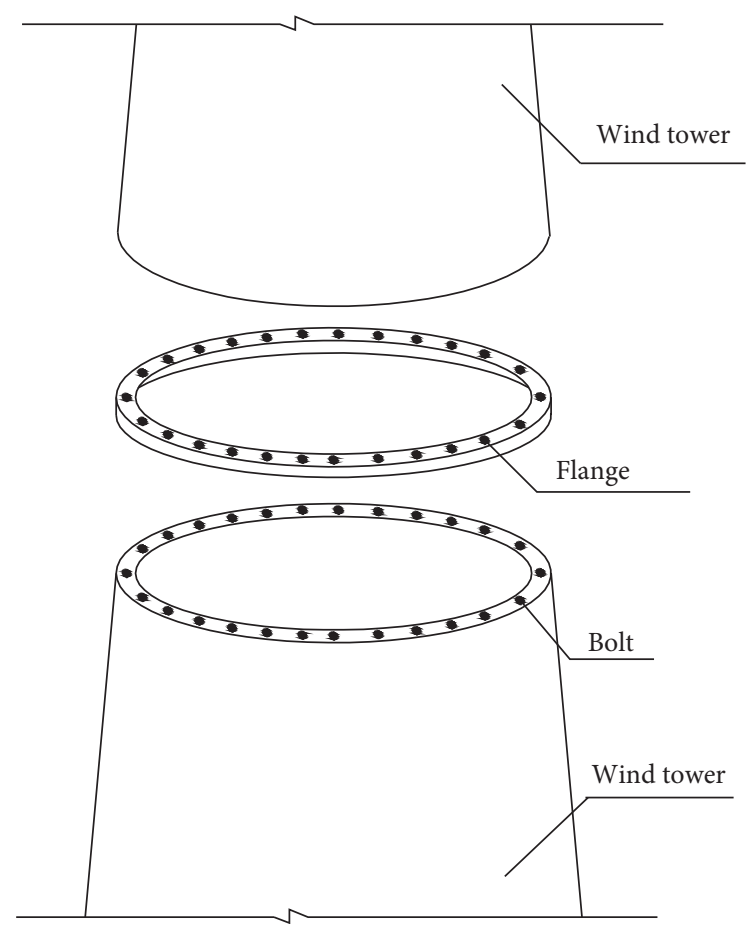

FIGURE 2: Flange connection of wind tower.

methods such as ultrasonic, acoustic emission, and X-ray. Therefore, Ahuir-Torres et al. [31] designed a wireless intelligent sensor network system for the corrosion detection of offshore wind turbine towers with the application of realtime remote sensing technology. The electrochemical properties of the structure will change when it is corroded, which will be detected by electrochemical sensors. Therefore, combined with real-time remote sensing technology, the system is able to detect the corrosion of offshore wind turbine towers remotely. In addition, the study obtained the corrosion threshold under different environmental conditions through laboratory corrosion tests [32] and verified its reliability through a large amount of data in published papers.

\section{Application of Nondestructive Technologies in Wind Turbine Towers}

In Section 1, the common quality problems of the wind tower and relevant investigations are introduced. These investigations mainly focus on the specific detection methods, detection indexes, the verification of tests, and finite element models. In this section, the basic principles of several nondestructive testing technologies widely applied in wind tower are briefly introduced.

3.1. Ultrasonic Phased Array Detection Technology. Ultrasonic phased array is a relatively advanced ultrasonic nondestructive testing technology. The probe of phased array imaging is composed of a set of independent wafers, which are agitated by the electrical system according to a certain time sequence. During the receiving process of reflected waves, the chip unit is also controlled according to a certain time sequence and the reflected signal is synthesized and displayed. Ultrasonic phased array detection can realize sound beam deflection through delay technology, that is, by controlling the time delay of excitation, receiving pulses of each crystal unit and changing the phase relation of each chip when transmitting ultrasonic to and receiving it from a certain point in the object [33] (see Figure 3). In that case, general ray tracing models are currently required to calculate the proper incident angle of single element probes and the proper time delay of phased array [34].

Traditional steel wind turbine towers generate a large part of the wind power market. Welding is an important connection method for pieces of steel wind towers. Ultrasonic phased array technology is often used to detect the quality of the welding seam. The study shows that when testing the welding seam of steel wind towers, the echo signal of the ultrasonic phased array can be extracted, processed, and transformed to achieve a better effect of classification and recognition of flaw [35].

Wang [36] compared the detection effect of the ultrasonic phased array, TOFD, and DR technologies on the same weld of wind towers and found out that the on-site detection efficiency of ultrasonic phased array technology was higher than the other two, and it could be more efficient to detect the continuous trend of defects in the weld. Results showed that the detection efficiency of ultrasonic phased array technology is higher than the other two, which can detect the continuous trend of flaws in the weld more clearly. However, this technique has its limitations in repeatability accuracy, that is, the value of the same flaw varies when repeating detection. In addition, although this method is accurate in the qualitative analysis of flaws, it is difficult to calculate the defects quantitatively.

3.2. TOFD Detection Technology. Time of flight diffraction (TOFD) is also a type of ultrasonic nondestructive testing technology widely applied for the detection of weld quality due to its safety (no ionizing radiation) and reliability [37], which detects the flaws using a diffraction wave generated by an ultrasonic wave at the end of the flaws. During detection, a pair of probes with the same frequency, angle, and size are placed symmetrically on both sides of the weld, with one as the transmitting probe and the other as the receiving one. The transmitting probe induces longitudinal waves into the weld to be detected and generates three types of waves: straight wave, which propagates along the weld surface; reflected wave, reflected from the floor of the component; and diffraction waves, which pass through the two ends of the flaw as shown in Figure 4.

Therefore, if there is a flaw in the weld with sufficient length, the receiving probe will detect four different wave patterns with a time difference between each pattern [38].

TOFD technology has a high defect detection rate, as well as accuracy in location and quantification of defects [39]. According to its principle, the size of a flaw can be calculated based on the time difference and accurately located based on simple geometric relationships; therefore, it is 


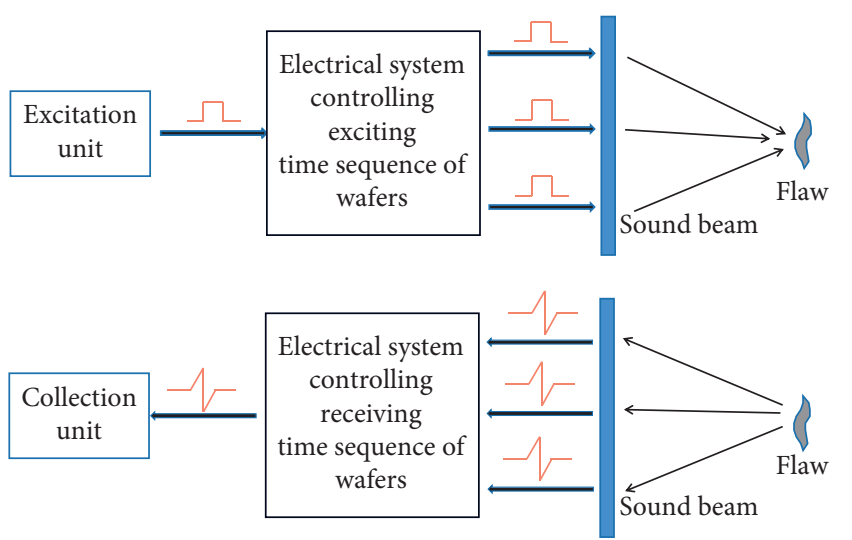

(a)

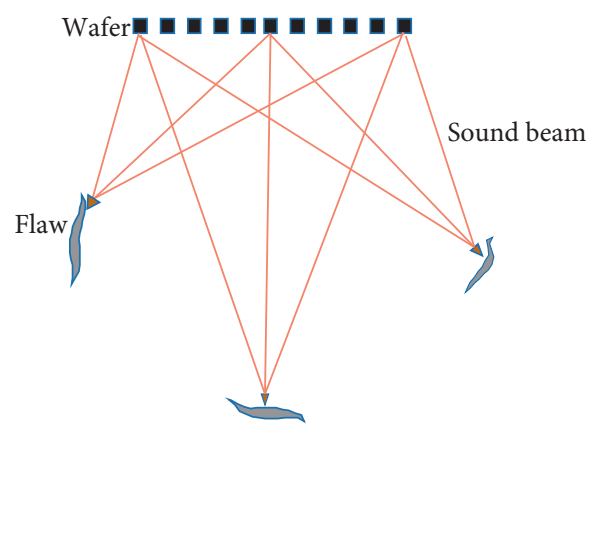

(b)

FIgURE 3: Principle of ultrasonic phased array scanning. (a) Exciting and receiving signals according to a certain time sequence. (b) Deflection of the sound beam.

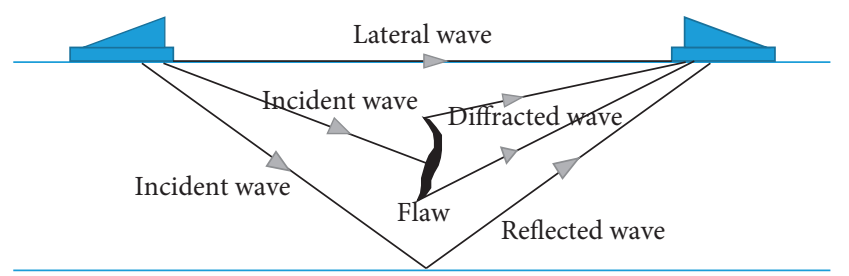

FIgURE 4: Principle of TOFD acoustic detection.

widely used in the detection of weld quality. Ma et al. [40] derived the formula for quantitative calculation of tilt crack length and angle for thick-walled tubular detected by TOFD. The study has certain reference significance for the detection and calculation of flaws of wind towers which is exactly a thick-walled tubular structure.

However, there are still some technical difficulties when applying TOFD detection technology to the weld quality detection of wind turbine towers due to the difficulties in receiving diffraction waves diffracted by weld surface and the end of some lateral defects. Therefore, there are certain blind regions in the detection of these areas. In addition, when detecting the continuous weld at the transition between flange and tower, it is necessary to use other detection methods to carry out corresponding supplementary detection since the ultrasonic probe cannot be placed on the flange side [41].

3.3. Magnetic Memory Detection Technology. Magnetic memory detection technology is a new nondestructive method introduced in the field of wind turbine towers in China. This technology is easy to carry out and has a low cost $[42,43]$, which can be used in the maintenance of wind tower tubes to improve their detection rate and to reduce the maintenance cost.

The principle of this detection technology is to utilize the magnetic characteristics of the geomagnetic field. The flaw will form stress concentration areas, which will produce spontaneous magnetization under the combined action of stress and geomagnetic field. The spontaneously magnetized magnetism will not completely disappear, maintaining some residual magnetism even though the stress disappears [44], which is called magnetic memory. In the region of concentrated stress, the normal component of magnetic memory signal $H_{p}(Y)$ changes considerably [45], with its peak value changing from positive to negative as shown in Figures 5 and 6 . Therefore, the stress concentration area where the flaw is located can be determined according to the amplitude of the normal component of the magnetic memory signal detected by the magnetic sensitive probe.

Since the magnetic memory is a characteristic of ferromagnetic materials, it is mainly used in the inspection for the quality of the weld and the flange of a traditional steel wind tower as well as the steel components in concrete towers. The specific detection method is to manually push the magnetic memory trolley and try to keep a uniform speed through the welding seam and flange connection to carry out magnetic memory scanning.

It should be noted that this technology has its limitations; firstly, the magnetic memory signal is relatively weak and influenced by many factors when used for stress analysis. The mechanism has not been clarified $[46,47]$ and the magnetic properties of materials vary a lot with different ferromagnetic materials and environmental characteristics of the site where the wind tower is located, causing the accuracy of detection results to be controversial.

3.4. Acoustic Emission Technology. Acoustic emission technology (AE) is a dynamic nondestructive testing technology. Different from other ultrasonic testing technology, it is based on the characteristics of the material itself that the plastic deformation of most metal materials will produce acoustic emission phenomenon [48]. As shown in Figure 7, the material will release elastic waves when it is deformed or fractured, which propagate to the component surface, causing mechanical vibration. Additionally, vibration is converted into electrical signals through the sensor and amplified by the preamplifier. These signals are recorded and processed and finally used as the basis for data analysis and evaluation of defect characteristics [49]. 


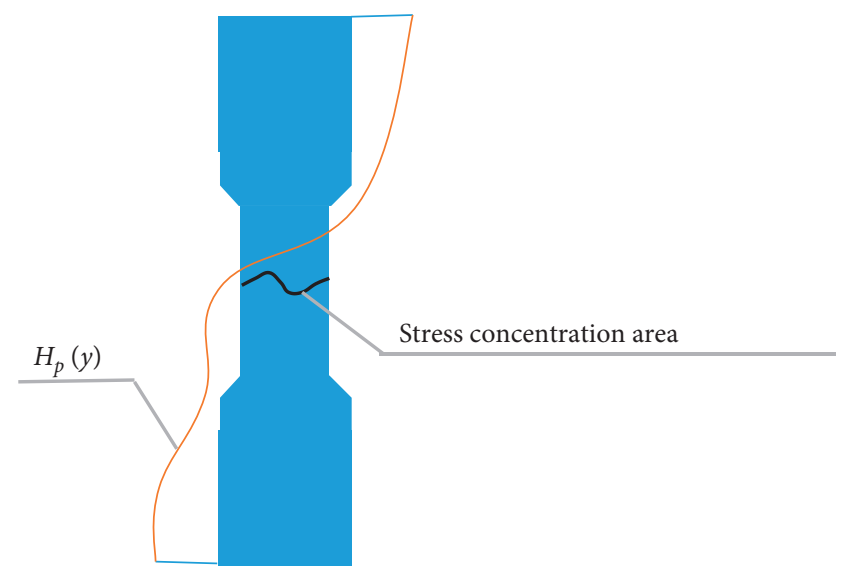

FIGURE 5: Relationship between stress concentration and normal component $H_{p}(Y)$ of magnetic memory signal.

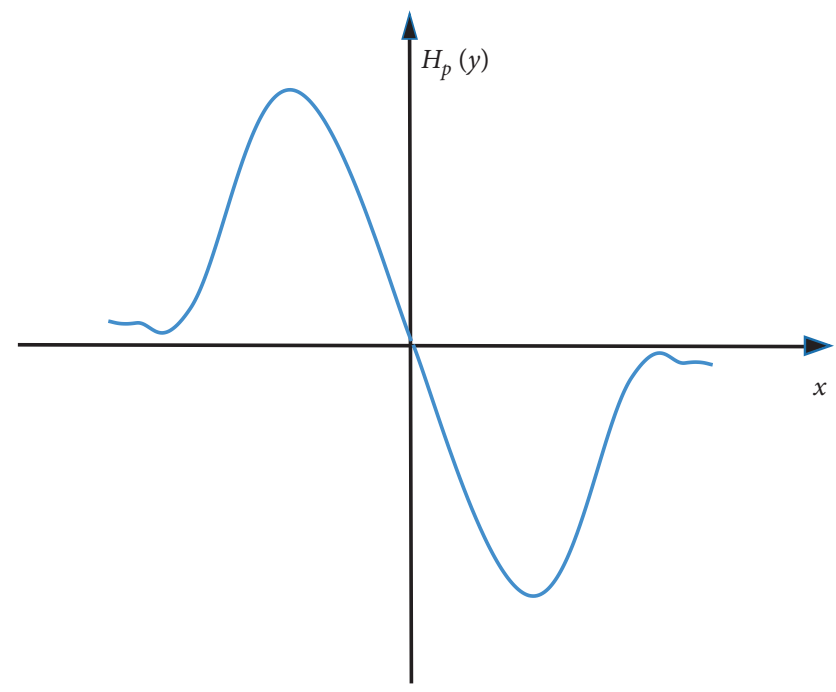

FIGURE 6: Change of normal component $H_{p}(Y)$ peak of magnetic memory signal in the stress concentration area.

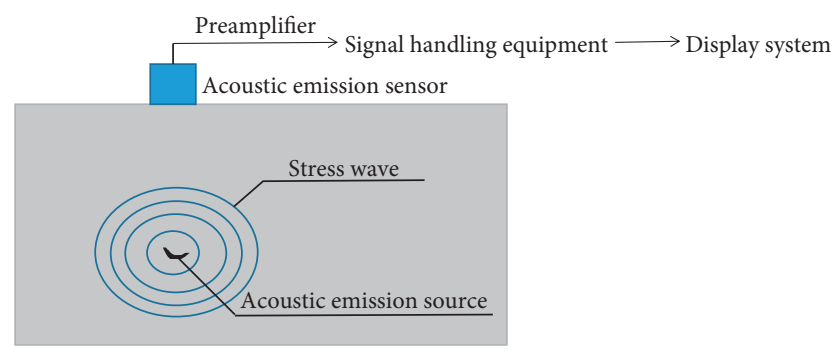

Figure 7: Principle of acoustic emission technology.

Other traditional nondestructive testing methods are difficult to achieve the early detection of flaws, which can be easily realized by acoustic emission testing technology. The elastic wave varies with the change of defects and deformation of the component making the technology sensitive to dynamic defects. Therefore, using acoustic emission instruments to detect, record, and analyze acoustic emission sources can detect the defects of wind towers in a timely manner in the initiation and propagation and effectively evaluate dynamic damage of defects to prevent sudden adversity of the structure [50]. Acoustic emission technology can be used for weld quality detection as well as detection of the generation and expansion of concrete cracks [51]; therefore, it can be applied in the detection of both steel and concrete wind towers.

When using acoustic emission technology to detect components compared with other methods, the energy is released from its stress-strain energy without external power. The dynamic monitoring of components can be realized by detecting the crack at the beginning of its propagation process and the change of the cracks [52]. In addition, acoustic emission detection does not require additional downtime and has the advantage of simplicity, convenience, and economy which can effectively change the traditional detection method of wind towers. However, due to the complex working environment of the fan tower tube and the presence of many external disturbances, AE signals may contain some mechanical and environmental noise. The way to eliminate the noise and extract AE signals with typical defects of effective AE signals to accurately reflect the state of defects remains to be further studied [53].

3.5. Fiber Bragg Grating Technology. A fiber Bragg grating is a type of fiber which is processed by special technology. The refractive index of a certain part of the structure (Bragg grating) changes periodically, playing a role in light wave selection [54]. As shown in Figure 8, when a beam of light with a wide spectrum passes through the grating, the light satisfying a certain condition is reflected by the grating, which will change with the change of strain or temperature of the environment where the grating is located, leading to the transfer of central wavelength of the reflected wave. Therefore, by measuring the change value of the central wavelength of the reflected wave, the strain of the measured structure can be deduced [55].

The strain sensor made of grating fiber technology has the advantage of high sensitivity, high antielectromagnetic interference, and strong repeatability [56] and is widely used in structural strain measurement. As mentioned in Section 2.2, fiber Bragg grating sensors are often used in deformation monitoring in wind towers. However, since they are sensitive to temperature, using fiber Bragg grating sensors to detect structural strain in areas with large temperature variations may be inaccurate.

3.6. Piezoelectric Impedance Technology. The piezoelectric sensor used to detect loose bolts introduced in Section 2.3 is based on the piezoelectric impedance technology, which is based on the piezoelectric effect of piezoelectric materials as shown in Figure 9. The piezoelectric material is attached to the surface of the structure to be detected, and an electric excitation signal known as the inverse piezoelectric effect is applied to the piezoelectric material to make it vibrate slightly. The vibration is transmitted to the surface of the structure to be measured and causes the structure to vibrate. The vibration of the structure to be measured reacts on the 


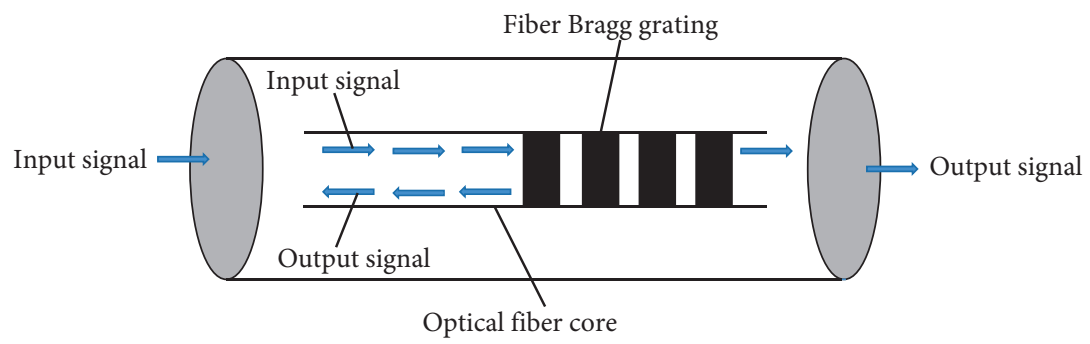

Figure 8: Principle of fiber grating technology.

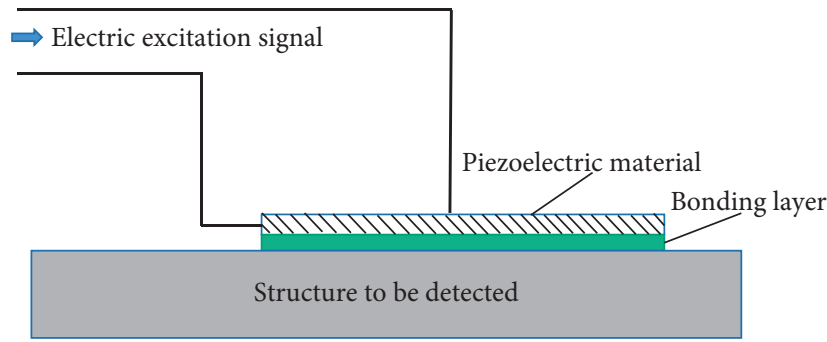

Figure 9: Principle of piezoelectric impedance detection technology.

TABLE 1: Summary of nondestructive testing technologies.

\begin{tabular}{|c|c|c|c|c|}
\hline $\begin{array}{l}\text { Nondestructive } \\
\text { testing } \\
\text { technologies }\end{array}$ & Principle & Advantages & Limitations & $\begin{array}{l}\text { Applications in } \\
\text { wind turbine } \\
\text { tower }\end{array}$ \\
\hline $\begin{array}{l}\text { Ultrasonic phased } \\
\text { array detection }\end{array}$ & $\begin{array}{l}\text { A set of independent wafers } \\
\text { inducing ultrasonic waves } \\
\text { independently, and deflection of } \\
\text { an acoustic beam is realized by } \\
\text { delay technique }\end{array}$ & $\begin{array}{l}\text { Suitable for detection of } \\
\text { structures that are difficult to } \\
\text { access, accurate localization of } \\
\text { defects, high sensitivity of } \\
\text { detection }\end{array}$ & $\begin{array}{l}\text { Poor repeatable accuracy, } \\
\text { difficult to calculate the flaws } \\
\text { quantitatively }\end{array}$ & $\begin{array}{c}\text { Detection of } \\
\text { welding seam }\end{array}$ \\
\hline TOFD detection & Huygens principle & $\begin{array}{l}\text { High defect detection rate, } \\
\text { accurate location and } \\
\text { quantified calculation of flaws }\end{array}$ & $\begin{array}{l}\text { Blind spots of detection in the } \\
\text { surface, probe cannot be } \\
\text { placed at the continuous weld } \\
\text { between flange and the tower }\end{array}$ & $\begin{array}{c}\text { Detection of } \\
\text { welding seam }\end{array}$ \\
\hline Magnetic memory & $\begin{array}{l}\text { Magnetic memory properties of } \\
\text { ferromagnetic materials }\end{array}$ & $\begin{array}{l}\text { Improvement of detection } \\
\text { rate, reduction of the } \\
\text { detection cost }\end{array}$ & $\begin{array}{l}\text { Magnetic memory signal is } \\
\text { weak and may be influenced } \\
\text { by many factors }\end{array}$ & $\begin{array}{l}\text { Detection of } \\
\text { welding seam } \\
\text { and flanges }\end{array}$ \\
\hline Acoustic emission & $\begin{array}{c}\text { Elastic waves are released from } \\
\text { the flaws of material }\end{array}$ & $\begin{array}{c}\text { No external energy is needed, } \\
\text { less affected by the } \\
\text { environment. The dynamic } \\
\text { tracking of flaws }\end{array}$ & $\begin{array}{l}\text { Mixture of mechanical and } \\
\text { environmental noise with AE } \\
\text { signals }\end{array}$ & $\begin{array}{c}\text { Monitoring } \\
\text { during its whole } \\
\text { life cycle }\end{array}$ \\
\hline Fiber Bragg grating & $\begin{array}{c}\text { The selection of a grating for a } \\
\text { particular light }\end{array}$ & $\begin{array}{l}\text { High sensitivity, strong anti- } \\
\text { EMI capability }\end{array}$ & $\begin{array}{c}\text { Sensitive to temperature of the } \\
\text { environment }\end{array}$ & $\begin{array}{c}\text { Deformation } \\
\text { monitoring }\end{array}$ \\
\hline $\begin{array}{l}\text { Piezoelectric } \\
\text { impedance }\end{array}$ & Piezoelectric effect & $\begin{array}{l}\text { No external excitation is } \\
\text { required, sensitive to small } \\
\text { changes of measured } \\
\text { structural parameters }\end{array}$ & $\begin{array}{l}\text { Easily affected by } \\
\text { environmental factors and the } \\
\text { stability of detection needs to } \\
\text { be improved }\end{array}$ & $\begin{array}{l}\text { Detection of } \\
\text { flange bolt } \\
\text { looseness }\end{array}$ \\
\hline
\end{tabular}

piezoelectric material, making a change to the surface charge and the output electrical signal, which is detected by the impedance analyzer, namely, the positive piezoelectric effect [57].

When the bolt is applied with pretightening force, the stiffness of the piezoelectric sensor mounted on the bolt head will decrease under the action of compressive stress, reducing the resonance frequency of some orders of the system composed of the bolt head and piezoelectric sensor [58]. On the contrary, there will be a loss of pretightening force if the bolt becomes loose, increasing the measured peak frequency of the system. Therefore, a piezoelectric impedance sensor is often used to detect the bolt loosening of the flange, as introduced in Section 2.3.

The positive and negative piezoelectric effects of the piezoelectric material enable excitation and sensor without external excitation; in addition, the technology is sensitive to small changes in measured structural parameters [59] and 
efficient in detection, so it is widely used in various engineering fields. However, the amplitude of piezoelectric impedance is easily affected by environmental factors, and the detection stability needs to be improved [58].

The principles, advantages, limitations, and applications in wind turbine towers of the above nondestructive testing techniques are summarized in Table 1.

\section{Conclusions}

The wind tower is an important structure of wind turbines, in which quality and health are related to the normal operation of wind turbines. This paper summarizes several common quality problems of wind towers, including damage, deformation, loosening of flange bolts, corrosion of offshore towers, and potential hazards. It also introduces several investigations on the corresponding specific detection and monitoring methods for these problems. Most of these investigations are based on theoretical analysis combined with finite element simulations or experiments. However, the accuracy and stability of these methods still need to be improved when used in wind tower health detection and monitoring, considering the particularity of the wind tower components. It is a good idea to further improve the technology by combining comprehensive investigations on other types of structures and then apply it to wind towers, which needs further studies. In addition, several nondestructive testing technologies are introduced including ultrasonic phased array, magnetic memory, acoustic emission, fiber Bragg grating, and piezoelectric impedance. Furthermore, it is summarized their principle advantages, limitations, and applications in wind turbine towers. These techniques have been developed after long-term practice and application in many engineering fields; however, they are not widely used in wind towers and have their own limitations. For instance, the way to improve their limitations and extend their application in the detection of all parts of the wind tower will be the focus of future research.

\section{Data Availability}

The data used to support the findings of this study are included within the article.

\section{Conflicts of Interest}

There are no conflicts of interest regarding the publication of this paper.

\section{Acknowledgments}

This work was financially supported by the National Science Foundation of China (51909205) and the Chinese Postdoctoral Science Foundation (2018M631166 and 2019T120914).

\section{References}

[1] K. Dai, Y. Wang, Y. Wang, W. Zhu, and Y. Xu, "Development of a modified stochastic subspace identification method for rapid structural assessment of in-service utility-scale wind turbine towers," Wind Energy, vol. 20, no. 10, pp. 1687-1710, 2017.

[2] J. J. Li, X. Q. Wu, and B. Chen, "Review of wind power generation and relative technology development," Electric Power Construction, vol. 32, no. 8, pp. 64-72, 2011.

[3] Y. Zhang, X. Cai, Q. Gao, and W. X. Ding, "Research summary of wind turbine tower structure," Chinese Journal of Engineering Design, vol. 23, no. 2, pp. 108-115, 2016.

[4] W. Hu, R. J. Barthelmie, F. Letson, and S. C. Pryor, "A new seismic-based monitoring approach for wind turbines," Wind Energy, vol. 22, no. 4, pp. 473-486, 2019.

[5] R. N. Soman, P. H. Malinowski, and W. M. Ostachowicz, "Biaxial neutral axis tracking for damage detection in windturbine towers," Wind Energy, vol. 19, no. 4, pp. 639-650, 2016.

[6] B. Keshtegar, M. Bagheri, C. W. Fei, C. Lu, O. Taylan, and T. Duc-Kien, "Multi-extremum-modified response basis model for nonlinear response prediction of dynamic turbine blisk," Engineering with Computers, vol. 169, 2021.

[7] L. Han, C. Chen, T. Y. Guo et al., "Probability-based service safety life prediction approach of raw and treated turbine blades regarding combined cycle fatigue," Aerospace Science and Technology, vol. 110, Article ID 106513, 2021.

[8] C. W. Fei, H. T. Liu, S. L. Li, H. Li, L. Q. An, and C. Lu, "Dynamic parametric modeling-based model updating strategy of aeroengine casings," Chinese Journal of Aeronautics, 2020.

[9] Y. He, S. Guo, and X. Zhang, "Study on the measurement method of the crack local flexibility of the beam structure," Shock and Vibration, vol. 2020, Article ID 8816884, 7 pages, 2020.

[10] H. B. Bisheh, G. G. Amiri, and E. Darvishan, "Ensemble classifiers and feature-based methods for structural damage assessment," Shock and Vibration, vol. 2020, Article ID 8899487, 14 pages, 2020.

[11] H. P. Zhu, J. Yu, and J. B. Zhang, "A summary review and advantages of vibration-based damage identification methods in structural health monitoring," Engineering Mechanics, vol. 28, no. 2, pp. 11-17, 2011.

[12] J. Pacheco, G. Oliveira, F. Magalhaes, C. Moutinho, and A. Cunha, "Evaluation of low cost vibration based damage detection systems," Journal of Physics Conference Series, vol. 1037, 2018.

[13] H. Kim, M. Kim, and D. Choe, "Structural health monitoring of towers and blades for floating offshore wind turbines using operational modal analysis and modal properties with numerical-sensor signals," Ocean Engineering, vol. 188106226 pages, 2019.

[14] W. Kim, J.-H. Yi, J.-T. Kim, and J.-H. Park, "Vibration-based structural health assessment of a wind turbine tower using a wind turbine model," Procedia Engineering, vol. 188, pp. 333-339, 2017.

[15] W.-H. Hu, S. Thöns, R. G. Rohrmann, S. Said, and W. Rücker, "Vibration-based structural health monitoring of a wind turbine system Part II: environmental/operational effects on dynamic properties," Engineering Structures, vol. 89, pp. 273-290, 2015.

[16] M. Benedetti, V. Fontanari, and D. Zonta, "Structural health monitoring of wind towers: remote damage detection using strain sensors," Smart Materials and Structures, vol. 20, Article ID 0550095, 2011.

[17] N. X. Ren and J. P. Ou, “A crashworthy device against shipOWT collision and its protection effects on the tower of 
offshore wind farms," China Ocean Engineering, vol. 23, no. 4, pp. 593-602, 2009.

[18] Z. Y. Su, J. R. Zhao, L. L. Wang, and W. Liu, "Discussion on the application of Tian bao TX8 3D laser scanner in the vertical monitoring of fan tower in wind power plant," Bulletin of Surveying and Mapping, vol. 10, pp. 146-147, 2016.

[19] H. Q. Xie, Y. Tang, D. W. Xu, Y. Z. Qin, X. Lu, and C. Wang, "Experimental study on the tilt of wind turbine tower by using laser point cloud data," Bulletin of Surveying and Mapping, vol. 12, pp. 38-42, 2017.

[20] H.-J. Bang, H.-I. Kim, and K.-S. Lee, "Measurement of strain and bending deflection of a wind turbine tower using arrayed FBG sensors," International Journal of Precision Engineering and Manufacturing, vol. 13, no. 12, pp. 2121-2126, 2012.

[21] A. Turner and T. W. Graver, "Structural monitoring of wind turbine blades using fiber optic Bragg grating strain sensors," Experimental Mechanics on Emerging Energy Systems and Materials, vol. 5, pp. 149-154, 2011.

[22] B. Shan, N. Ren, and Z. Xue, "Stereovision-based surface deformation detection of offshore wind turbine model under ship impact," Measurement, vol. 131, pp. 605-614, 2019.

[23] X. L. He, T. L. She, B. Xu, J. Li, G. Chen, and G. F. Cao, "Method for detecting bolts looseness of a wind turbine tower based on its vibration characteristics," Journal of Vibration and Shock, vol. 35, no. 14, pp. 112-118, 2016.

[24] K. Chen, Numerical Analysis of the Influence of Flange Bolt Loosening on Structural Vibration of Wind Power Tower, Institute of Engineering Mechanics, China Seismological Bureau, Beijing, China, 2019.

[25] T. Tang, M. J. Hua, X. Jiang, Y. X. Zhang, and X. Zhang, "Study on improved damage index to evaluate bolt loosening of flange structure," Journal of Beijing University of Aeronautics and Astronautics, vol. 47, no. 1, pp. 123-131, 2021.

[26] T.-C. Nguyen, J.-H. Huynh, and J.-T. Kim, "Hybrid boltloosening detection in wind turbine tower structures by vibration and impedance responses," Wind and Structures, vol. 24, no. 4, pp. 385-403, 2017.

[27] J.-H. Park, T.-C. Huynh, S.-H. Choi, and J.-T. Kim, "Visionbased technique for bolt-loosening detection in wind turbine tower," Wind and Structures, vol. 21, no. 6, pp. 709-726, 2015.

[28] B. P. Feng, B. Y. Liu, and C. K. Chen, "Discussion on anticorrosion design of offshore and onshore wind farms at home and abroad," Corrosion Science and Protection Technology, vol. 25, no. 4, pp. 343-346, 2013.

[29] S. J. Price and R. B. Figueira, "Corrosion protection systems and fatigue corrosion in offshore wind structures: current status and future perspectives," Coatings, vol. 7252 pages, 2017.

[30] E. Smilden, S. H. Sørum, E. E. Bachynski, A. J. Sørensen, and J. Amdahl, "Post-installation adaptation of offshore wind turbine controls," Wind Energy, vol. 23, no. 4, pp. 967-985, 2020.

[31] J. I. Ahuir-Torres, N. Bausch, A. Farrar et al., "Benchmarking parameters for remote electrochemical corrosion detection and monitoring of offshore wind turbine structures," Wind Energy, vol. 22, no. 3, pp. 857-876, 2019.

[32] J. I. Ahuir-Torres, S. Simandjuntak, N. Bausch et al., "Corrosion threshold data of metallic materials in various operating environment of offshore wind turbine parts (tower, foundation, and nacelle/gearbox)," Data in Brief, vol. 25, Article ID 104207, 2019.

[33] C. Z. Xie, Z. L. He, Y. X. Ling, L. C. Li, Z. F Zhang, and R. H. Li, "Using ultrasonic phased array to inspect the internal defects of composite insulators," Proceedings of the CSEE, vol. 32, no. 1, pp. 63-68, 2012.

[34] C. Mineo, D. Lines, and D. Cerniglia, "Generalised bisection method for optimum ultrasonic ray tracing and focusing in multi-layered structures," Ultrasonics, vol. 111, p. 106330, 2021.

[35] X. D. Ma, P. L. Zhang, T. P. Xu, and T. Y. Yang, "Research on weld defects detection based on ultrasonic phased array," Hot Working Technology, vol. 49, no. 5, pp. 150-154, 2020.

[36] J. S. Wang, "Preliminary study on the application of ultrasonic phased array detection technology to weld detection of wind turbine tower," in Proceedings of the Sixth China Wind Power Post-market Exchange and Cooperation Conference, pp. 104107, Tianjin, China, 2019.

[37] F. Roca Barceló, P. Jaén del Hierro, F. Ribes Llario, and J. Real Herráiz, "Development of an ultrasonic weld inspection system based on image processing and neural networks," Nondestructive Testing and Evaluation, vol. 33, no. 2, pp. 229-236, 2018.

[38] W. Q. Li, F. C. Ma, M. Y. Zhang, and L. Yang, "Research of a new method for ultrasonic non-destructive testing," Journal of Taiyuan University of Technology, vol. 42, no. 2, pp. 126-129, 2011.

[39] B. Gauthier, G. Painchaud-April, A. Le Duff, and P. Belanger, "Towards an alternative to time of flight diffraction using instantaneous phase coherence imaging for characterization of crack-like defects," Sensors (Basel, Switzerland), vol. 21, no. 3, 2021.

[40] T. T. Ma, L. Lin, D. H. Zhang, Y. Yan, and S. J. Jin, “Accurate quantification of inclined cracks in thick-walled pipes based on TOFD circumferential scanning," Chinese Journal of Scientific Instrument, vol. 40, no. 3, pp. 23-29, 2019.

[41] H. L. Cui, "Application of TOFD detection technology on wind power tower drum weld detection," Shandong Electric Power, vol. 42, no. 6, pp. 75-77, 2015.

[42] K. S. Xu, K. Yang, J. Liu, and Y. Wang, "Study on metal magnetic memory signal of buried defect in fracture process," Journal of Magnetism and Magnetic Materials, vol. 498166139 pages, 2020.

[43] K. Xu, X. Qiu, and X. Tian, "Theoretical investigation of metal magnetic memory testing technique for detection of magnetic flux leakage signals from buried defect," Nondestructive Testing and Evaluation, vol. 33, no. 1, pp. 45-55, 2018.

[44] D. Gong and G. Han, "Development of pipeline stress detection equipment based on magnetic memory method," Journal of Electronic Measurement and Instrumentation, vol. 33, no. 2, pp. 94-100, 2019.

[45] S. Y. Wan, Research on Magnetic Memory Detection Principle and its Application Technology, Huazhong University of Science and Technology, Wuhan, China, 2006.

[46] B. Liu, X. Xue, J. Li, R. Li, S. Dong, and J. Fang, "Grain size effect on metal magnetic memory signal for stress damage evaluation of low carbon steel," Nondestructive Testing and Evaluation, vol. 34, no. 3, pp. 267-282, 2019.

[47] B. Liu, P. Fu, R. F. Li, P. He, and S. Y. Dong, "Influence of crack size on stress evaluation of ferromagnetic low alloy steel with metal magnetic memory technology," Materials, vol. 12402824 pages, 2019.

[48] W. Suwansin and P. Phasukkit, "Deep learning-based acoustic emission scheme for nondestructive localization of cracks in train rails under a load," Sensors, vol. 212721 pages, 2021.

[49] Y. C. Jiang, Application Research of Acoustic Emission Technology in Wind Power Tower Tube Detection, Lanzhou University of Technology, Lanzhou, China, 2016. 
[50] P. L. Zhang, R. J. Liu, X. H. Wei, P. Kong, and H. Q. Deng, "Application and research of acoustic emission technology in dynamic monitoring of wind towers," Journal of Mechanical Strength, vol. 38, no. 3, pp. 470-474, 2016.

[51] P. Ming, J. Lu, X. Cai, M. Liu, and X. Chen, "Analysis of the crack evolution process in crumb rubber concrete based on acoustic emission technology," KSCE Journal of Civil Engineering, vol. 24, no. 7, pp. 2088-2098, 2020.

[52] X. C. Wei, Y. Chen, C. Lu, G. Chen, L. X. Huang, and Q. F. Li, "Acoustic emission source localization method for high-speed train bogie," Multimedia Tools and Applications, vol. 79, no. 21-22, pp. 14933-14949, 2020.

[53] P. Zhang, Y. Sang, and Z. Zhao, Z. Q. Zhao, Research based on the acoustic emission of wind power tower drum dynamic monitoring technology," Springer Proceedings in Physics, vol. 158, pp. 585-602, 2015.

[54] X. L. Kong, K. X. Liao, C. Xu, H. F. Lv, and X. F. Zhao, "Monitoring residual strain of concrete in freezing-thawing environment using FBG," Instrument Technique and Sensor, vol. 7, pp. 88-90, 2019.

[55] Y. Chen, Y. Lin, C. Li, and Q. Li, "Fiber Bragg grating strain sensor applied in security monitoring of road tunnel structure," Advances in Mechanical and Electronic Engineering, vol. 176, 2012.

[56] T. Wang, Z. Yuan, Y. Gong et al., "Fiber Bragg grating strain sensors for marine engineering," Photonic Sensors, vol. 3, no. 3, pp. 267-271, 2013.

[57] T. Wang, Z. W. Yang, J. H. Shao, and Y. R. Li, "Research on bolt loosen detection based on piezoelectric impedance technology," Chinese Journal of Sensors and Actuators, vol. 27, no. 10, pp. 1321-1325, 2014.

[58] J. H. Shao, T. Wang T, Z. A. Wang, D. L. Wei, and Y. R. Li, "Bolt looseness detection using piezoelectric impedance frequency shift method," China Mechanical Engineering, vol. 30, no. 12, pp. 1395-1399, 2019.

[59] J. H. Li, S. C. He, W. L. Chen, W. Yan, and B. Sun, "Identification and application of sleeve grouting plumpness based on piezoelectric impedance effect," China Civil Engineering Journal, vol. 53, no. 3, pp. 65-77, 2020. 